\title{
Dietary practices and nutritional status of 0-24-month-old children from Brazilian Amazonia
}

\author{
TG Castro ${ }^{1,2}$, LG Baraldi ${ }^{1}$, PT Muniz ${ }^{3}$ and MA Cardoso ${ }^{1, *}$
}

'Department of Nutrition, School of Public Health, University of São Paulo, Av. Dr Arnaldo 715, São Paulo, SP 01246-904, Brazil: ${ }^{2}$ Department of Social Medicine, School of Medicine, Federal University of Rio Grande do Sul, Porto Alegre, Brazil: ${ }^{3}$ Department of Health Sciences, Federal University of Acre, Rio Branco, Brazil

Submitted 5 May 2008: Accepted 11 December 2008: First published online 4 March 2009

\begin{abstract}
Objective: To assess the nutritional status and dietary practices of 0-24-month-old children living in Brazilian Amazonia.

Design: Cross-sectional study. Information on children's dietary intakes was obtained from diet history data. Weight and length were measured for anthropometric evaluation. Fe status was assessed using fasting venous blood samples; $\mathrm{Hb}$, serum ferritin and soluble transferrin receptor concentrations were measured. Setting: The towns of Assis Brasil and Acrelândia in the state of Acre, north-west Brazil.

Subjects: A total of sixty-nine randomly selected 0-24-month-old children.

Results: Of these children, $40 \cdot 3 \%$ were anaemic, $63 \cdot 1 \%$ were Fe-deficient, $28 \cdot 1 \%$ had Fe-deficiency anaemia and $11.6 \%$ were stunted. Breast-feeding was initiated by $97 \cdot 1 \%$ of mothers, followed by early feeding with complementary foods. The dietary pattern reflected a high intake of carbohydrate-rich foods and cow's milk, with irregular intakes of fruit, vegetables and meat. All infants and $92.3 \%$ of toddlers were at risk of inadequate Fe intakes. Fe from animal foods contributed on average $0.5 \%$ and $14.3 \%$ to total dietary Fe intake among infants and toddlers, respectively.

Conclusions: Poor nutritional status and inadequate feeding practices in this study population reinforce the importance of exclusive breast-feeding during the first 6 months of life. Greater emphasis is required to improve the bioavailability of dietary Fe during complementary feeding practices.
\end{abstract}

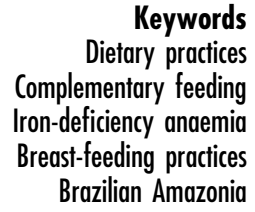

At about 6 months of age, the supply of energy and some nutrients from breast milk can no longer meet infants' needs, requiring the administration of complementary foods to achieve a well-balanced diet. Children aged 6-24 months are considered to be at the greatest nutritional risk due to poor feeding practices, with repercussions on their growth and development. Consequently, this age group is at increased risk of morbidity and mortality among young children ${ }^{(1-3)}$.

In developing countries it is difficult to achieve an adequate intake of several nutrients from complementary feeding, which is commonly based on traditional and unfortified foods $^{(4)}$. Previous studies have suggested that complementary foods are especially limited in micronutrients such as $\mathrm{Fe}, \mathrm{Zn}$ and $\mathrm{Ca}^{(1,4)}$.

Fe deficiency, the most common and widespread nutritional deficiency worldwide ${ }^{(3)}$, has been strongly related to dietary inadequacies during the first 2 years of life. In addition, in this critical period when the switch from a predominantly milk-based diet to one based on solid foods occurs, the increased risk for Fe deficiency is related to higher $\mathrm{Fe}$ requirements for growth and the depletion of Fe stores in this age group ${ }^{(5)}$.
Adequate assessment of feeding practices in children under 2 years of age requires data on breast-feeding patterns, dietary intakes and nutritional status indicators $^{(6)}$. To date, the relationship between biochemical Fe status, anthropometrical indicators and dietary intakes of young children in Amazonia has not been investigated. The only previously published survey on risk factors for anaemia and Fe deficiency in an Amazonian population did not assess food intakes ${ }^{(7)}$. Here we present an exploratory study about food intake and nutritional status of a randomly selected sample of 0-24-month-old children living in two towns in the Brazilian Amazon.

\section{Methods}

\section{Survey design and population}

In January 2003, a population-based cross-sectional study on child health and nutrition was carried out in the towns of Acrelândia and Assis Brasil, located respectively north-west Brazil. Subsistence agriculture and cattle-raising $350 \mathrm{~km}$ and $100 \mathrm{~km}$ from Rio Branco in the state of Acre, 
are the main local activities; coffee and banana are the predominant cash crops.

In these towns, all households with children less than 5 years of age were identified by a census performed by our field team. All eligible children were invited to participate in the main study. Data collected from 491 households (334 in Acrelândia and 157 in Assis Brasil) were available (100\% of eligible households). Sampling strategies and results of the survey are reported elsewhere ${ }^{(8)}$.

The survey included a structured face-to-face interview, usually with the child's mother, carried out by trained field workers. Questionnaires inquiring about socio-economic and demographic conditions, household environment, birth condition, breast-feeding initiation and morbidity during childhood (diarrhoea) were completed for 724 children. Diarrhoea occurrence was defined as the passage of frequent loose or liquid stools in the $15 \mathrm{~d}$ prior to the survey as reported by the child's caregiver, and was categorised as 'yes' or 'no'. Of the interviewed children, 677 provided blood samples (94\% of those eligible) and comprised the population further analysed in the main study.

Owing to limited resources, we decided to select at random a sub-sample of households with children below 2 years of age. Of the 250 children aged $<2$ years in the main study, $30 \%$ (seventy-five participants) were randomly selected with stratification by sex in each town to collect detailed information about breast-feeding and complementary feeding practices. The study was approved by the ethical review board of the School of Public Health of the University of São Paulo, Brazil. Written informed consent was obtained from the primary caregiver for each child participating in the study.

\section{Antbropometry}

Length and weight were measured by trained research assistants following standardized procedures and using calibrated equipment ${ }^{(9)}$. Recumbent length was measured on an infant measuring board (model 98-702; Seritex, Carlstadt, NJ, USA) and recorded to the nearest $0 \cdot 1 \mathrm{~cm}$. Weight was taken on a digital paediatric scale (Soehnle, Murrhardt, Germany) and recorded to the nearest $0.05 \mathrm{~kg}$. Each measurement was repeated and the mean value was calculated. Birth date was recorded directly from the birth certificate or child health card.

The $Z$-scores for length-for-age (LAZ), weight-for-age (WAZ) and weight-for-length (WLZ) were calculated using the DOMEANS procedure in the EPI-Info software version 6.04 (Centers for Disease Control and Prevention, Atlanta, GA, USA) ${ }^{(10)}$. Anthropometric cut-offs were analysed according to Onis et $a l^{(11)}$.

\section{Fe nutritional status}

A fasting venous blood sample was collected from each child. Hb concentration was measured using a HemoCue photometer (HemoCue AB, Angelholm, Sweden) at the study site. Serum samples were then transported on dry ice to São Paulo, where concentrations of serum ferritin (SF) and soluble transferrin receptor (sTfR) were measured using commercial enzyme immunoassay kits (Ramco Laboratories, Houston, TX, USA). The normal range of sTfR levels determined by the manufacturer was $2.9-8.3 \mathrm{mg} / \mathrm{l}$.

Anaemia, Fe deficiency and Fe-deficiency anaemia were defined on the basis of $\mathrm{Hb}, \mathrm{SF}$ and STfR values. Anaemia was defined according to the WHO cut-off value for children $>6$ months of age ( $\mathrm{Hb}$ concentration $<11 \cdot 0 \mathrm{~g} / \mathrm{dl})$. Fe deficiency was diagnosed when $\mathrm{SF}<12$ $\mu \mathrm{g} / \mathrm{l}$ and $\mathrm{sTfR}>8.3 \mathrm{mg} / \mathrm{l}$. The definition for Fe-deficiency anaemia was identical, except $\mathrm{Hb}$ had to be $<11.0 \mathrm{~g} / \mathrm{dl}$ for children $>6$ months of age ${ }^{(3,12)}$. Anaemic children detected during the survey received adequate treatment with ferrous sulfate, prescribed by the medical team involved in the project.

\section{Breast-feeding and complementary feeding practices}

Breast-feeding and complementary feeding practices were evaluated by trained nutritionists. The dietary intakes of the infants and toddlers were obtained using a diet history tool ${ }^{(13)}$. Weighed food portions were obtained using accurate scales (precision $1 \mathrm{~g}$ ) to derive the recipes mentioned in the diet history. This methodology permitted estimation of the quantity of different foods used in the recipes. The use of diet history data enabled minimization of the day-by-day variability, where instead of asking the caregiver 'What did the child eat yesterday?', the question was 'What does the child usually eat?'. The intake of breast milk volume was estimated using the following formula developed from children living in developing countries ${ }^{(14,15)}: Y=489-0 \cdot 63 X+13 \cdot 45 Z$ (where $Y$ is the predictor of breast-feeding intake in $\mathrm{ml} / \mathrm{d}$, $X$ is the age in months and $Z$ is the number of breastfeeding episodes during the day).

The database of the World Food Dietary Assessment System (WFood version 2.0; Office of Technology Licensing, University of California at Berkeley, Berkeley, CA, USA) was used to estimate the nutrient composition of diets. The nutrient database was based on the US Department of Agriculture (USDA) publications supplied by WFood, selecting databases for Mexican and Kenyan foods. All components (phytate, animal protein, Ca, tannin and ascorbic acid) necessary to estimate Fe and $\mathrm{Zn}$ bioavailability were included in the analyses. Since the Brazilian Food Composition Table is incomplete for many chemical components of interest, its use was limited to cooked beans (with broth) and non-enriched maize flour that could not be matched with foods from the WFood databases.

Using the WFood software, Zn bioavailability was calculated based on body basal requirements ${ }^{(16)}$. The bioavailability of haem Fe was calculated using the FAO/WHO estimate of $25 \%{ }^{(15)}$. For non-haem Fe, bioavailability was 
determined for each meal as previously described ${ }^{(1)}$. Daily energy and nutrient intakes from complementary foods and breast milk were compared with estimated needs determined in a recent review by Dewey and Brown $^{(6,17)}$. Values for the nutrient composition of breast milk were derived from the USDA database ${ }^{(18)}$.

Classification of breast-feeding categories was based on WHO criteria ${ }^{(19)}$ as follows. (i) Exclusive breast-feeding: only breast milk (including milk expressed or from a wetnurse), does not allow the infant to receive anything else, only drops and syrups; (ii) predominant breast-feeding: breast milk (including milk expressed or from a wetnurse) as the predominant source of nourishment, allows liquids, ritual fluids and drops or syrups; or (iii) breastfeeding: breast milk, allows any food or liquid including non-human milk.

\section{Statistical methods}

Variables are presented as proportions (\%), means (standard deviation) and medians (interquartile range) and were compared using $\chi^{2}$ tests, $t$ tests, ANOVA and MannWhitney tests. Information on the ownership of thirteen household assets was used to derive a wealth index; a derived variable used as a proxy of income in the domiciles. For this, principal components analysis was used to define the weights of household assets ${ }^{(20)}$ using the XLSTAT software version $7 \cdot 5 \cdot 2$ (Addinsoft, New York, NY, USA). The first principal component explained $32 \cdot 7 \%$ of the variability and gave the greatest weight to the ownership of a blender $(0 \cdot 345)$, a washing machine $(0 \cdot 327)$ and a refrigerator $(0 \cdot 311)$. After standardization of these weighted asset variables, the highest scores were associated with the ownership of a videotape player/recorder $(2 \cdot 865)$, a car $(2 \cdot 835)$ and a telephone $(1 \cdot 350)$. The lowest scores were given to households without a gas stove $(-4 \cdot 141)$, a refrigerator $(-1 \cdot 876)$ and a television $(-1 \cdot 833)$. The asset scores were summed to a wealth index for each household, which was divided into tertiles for further analysis. Frequencies of anaemia, Fe deficiency, Fe-deficiency anaemia and stunting were compared across tertiles of the wealth index.

The children were grouped into three age categories: infants (0-5 and 6-11 months) and toddlers (12-24 months). Due to non-normal distributions, dietary variables are expressed as median values and interquartile ranges according to age group. Proportions of children who met the recommended nutrient intakes ${ }^{(17)}$ were compared according to the wealth index tertiles. The dietary intakes were adjusted for total energy intake using the residual $\operatorname{method}^{(21)}$. Then, the median values for $\mathrm{Hb}$ and SF concentrations across tertiles of energy-adjusted nutrient intake levels were calculated. Frequencies of anaemia, Fe deficiency, Fe-deficiency anaemia and stunting were also compared across tertiles of energy-adjusted nutrient intakes.

Statistical analyses were performed using the SPSS statistical software package version $12 \cdot 0$ (SPSS Inc., Chicago,
IL, USA). All $P$ values were two-tailed and $P<0 \cdot 05$ was the level of significance.

\section{Results}

Among the seventy-five children enrolled in the present study, sixty-nine had complete information on the diet history questionnaire $(27 \cdot 6 \%$ of the total children under the age of 2 years in the main study). Of them, $50 \cdot 7 \%$ ( $n$ $35)$ were male. The mean (SD) age was $13 \cdot 4(6 \cdot 6)$ months. Twenty-five children $(33 \cdot 3 \%)$ were living in Assis Brasil and forty-six $(66 \cdot 7 \%)$ in Acrelândia. Among the heads of the family, $8 \cdot 1 \%$ had never studied at school, $14 \cdot 7 \%$ had studied for $<4$ years and $45.9 \%$ had between 4 and 8 years of formal education. In both towns there was no sanitation system. Overall, breast-feeding was initiated by $97 \cdot 1 \%$ of mothers, and twenty-six children (37.7\%) were breast-feeding at the time of the study. Among infants aged $0-5$ months, only two $(16 \cdot 2 \%)$ were exclusively breast-fed. The frequencies of breast-feeding according to age group were $66 \cdot 7 \%$ at $0-5$ months, $50 \cdot 0 \%$ at $6-11$ months and $23 \cdot 1 \%$ at $12-24$ months. Low prevalence $(4 \cdot 3 \%)$ of low birth weight $(<2500 \mathrm{~g})$ and high prevalence of recent diarrhoeal episodes $(39 \cdot 1 \%)$ were observed.

There were no significant differences in sociodemographic variables of the study children living in Assis Brasil and Acrelândia (Table 1). Table 2 presents characteristics of the nutritional status of the children according to age group. Overall, $69 \cdot 7 \%$ of the anaemia cases were due to Fe deficiency. A higher proportion of Fe deficiency was observed among toddlers (12-24 months) than among infants aged 6-11 months $\left(\chi^{2}\right.$, $P<0 \cdot 05)$. Mean values of anthropometric indices were in the normal range for infants ( $0-5$ and 6-11 months) and toddlers, without differences in these means according to age group (ANOVA, $P>0 \cdot 05$ ). The frequencies of morbidities (anaemia, Fe deficiency, Fe-deficiency anaemia,

Table 1 General characteristics of the children according to town, Acre, north-west Brazil

\begin{tabular}{|c|c|c|c|c|}
\hline \multirow[b]{2}{*}{ Variable } & \multicolumn{2}{|c|}{ Assis Brasil (n 23) } & \multicolumn{2}{|c|}{ Acrelândia (n 46) } \\
\hline & $n$ & $\%$ & $n$ & $\%$ \\
\hline \multicolumn{5}{|l|}{ Gender } \\
\hline Male & 11 & $47 \cdot 8$ & 24 & $52 \cdot 2$ \\
\hline Female & 12 & $52 \cdot 2$ & 22 & $47 \cdot 8$ \\
\hline \multicolumn{5}{|l|}{ Age groups (months) } \\
\hline $0-5$ & 3 & $13 \cdot 0$ & 9 & $19 \cdot 6$ \\
\hline $6-11$ & 7 & $30 \cdot 4$ & 11 & $23 \cdot 9$ \\
\hline $12-24$ & 13 & $56 \cdot 5$ & 26 & $56 \cdot 5$ \\
\hline \multicolumn{5}{|l|}{ Paternal schooling (years) } \\
\hline None & 1 & $4 \cdot 3$ & 4 & $8 \cdot 7$ \\
\hline $1-4$ & 4 & $8 \cdot 7$ & 14 & $35 \cdot 0$ \\
\hline$>4$ & 16 & $76 \cdot 2$ & 22 & $55 \cdot 0$ \\
\hline \multicolumn{5}{|l|}{ Inhabitants per household } \\
\hline$>4.5$ & 9 & $39 \cdot 1$ & 18 & $39 \cdot 1$ \\
\hline Drinking water treatment & 18 & $78 \cdot 3$ & 29 & $63 \cdot 0$ \\
\hline Public garbage collection & 21 & $91 \cdot 3$ & 38 & $82 \cdot 6$ \\
\hline
\end{tabular}


Table 2 Nutritional status of the children according to age, Acre, north-west Brazil

\begin{tabular}{|c|c|c|c|c|c|c|c|c|}
\hline & \multicolumn{2}{|c|}{$0-5$ months $(n 12)$} & \multicolumn{2}{|c|}{$6-11$ months ( $n$ 18) } & \multicolumn{2}{|c|}{$12-24$ months ( $n$ 39) } & \multicolumn{2}{|c|}{ All $(n 69)$} \\
\hline \multicolumn{9}{|l|}{ LAZ } \\
\hline Mean & \multicolumn{2}{|c|}{$-0 \cdot 19$} & \multicolumn{2}{|c|}{$0 \cdot 25$} & \multicolumn{2}{|c|}{$-0 \cdot 60$} & \multicolumn{2}{|c|}{-0.32} \\
\hline SD & \multicolumn{2}{|c|}{$1 \cdot 74$} & \multicolumn{2}{|c|}{$1 \cdot 35$} & \multirow{2}{*}{\multicolumn{2}{|c|}{$\begin{array}{c}1 \cdot 51 \\
15 \cdot 4(n 6)\end{array}$}} & \multirow{2}{*}{\multicolumn{2}{|c|}{$\begin{array}{c}1 \cdot 54 \\
11 \cdot 5(n 8)\end{array}$}} \\
\hline$\%$ of stunting $(\mathrm{LAZ}<-2)$ & \multicolumn{2}{|c|}{$16 \cdot 7(n 2)$} & \multicolumn{2}{|c|}{0} & & & & \\
\hline \multicolumn{7}{|l|}{ WAZ } & & \\
\hline Mean & \multirow{2}{*}{\multicolumn{2}{|c|}{$\begin{array}{r}-0.24 \\
1.24\end{array}$}} & \multicolumn{2}{|c|}{$0 \cdot 61$} & \multicolumn{2}{|c|}{$-0 \cdot 18$} & \multicolumn{2}{|c|}{0.01} \\
\hline $\mathrm{SD}$ & & & & & & & & 24 \\
\hline$\%$ of underweight $(\mathrm{WAZ}<-2)$ & \multicolumn{2}{|c|}{$8 \cdot 3(n 1)$} & \multicolumn{2}{|c|}{0} & \multicolumn{2}{|c|}{$7 \cdot 7(n 3)$} & \multicolumn{2}{|c|}{$5 \cdot 8(n 4)$} \\
\hline \multicolumn{9}{|l|}{ WLZ } \\
\hline Mean & \multicolumn{2}{|c|}{0.01} & \multicolumn{2}{|c|}{0.41} & \multicolumn{2}{|c|}{$0 \cdot 13$} & \multicolumn{2}{|c|}{$0 \cdot 18$} \\
\hline $\mathrm{SD}$ & \multirow{2}{*}{\multicolumn{2}{|c|}{$0 \cdot 77$}} & \multirow{2}{*}{\multicolumn{2}{|c|}{$\begin{array}{c}1.08 \\
5.6(n 1)\end{array}$}} & \multirow{2}{*}{\multicolumn{2}{|c|}{0.98}} & \multirow{2}{*}{\multicolumn{2}{|c|}{$\begin{array}{c}0.97 \\
1.4(n 1)\end{array}$}} \\
\hline$\%$ of wasting $(\mathrm{WLZ}<-2)$ & & & & & & & & \\
\hline \multirow[t]{2}{*}{$\%$ of overweight (WLZ $>2$ ) } & & & & & & & & $n$ 2) \\
\hline & $n$ & $\%$ & $n$ & $\%$ & $n$ & $\%$ & $n$ & $\%$ \\
\hline Anaemiat & - & & 9 & $50 \cdot 0$ & 14 & $35 \cdot 9$ & 23 & $33 \cdot 3$ \\
\hline Fe deficiency & 2 & $25 \cdot 0$ & 7 & 38.9 & 29 & $74 \cdot 3^{*}$ & 36 & $52 \cdot 2$ \\
\hline Fe-deficiency anaemiat & - & & 4 & $22 \cdot 2$ & 12 & $30 \cdot 8$ & 16 & $23 \cdot 2$ \\
\hline
\end{tabular}

LAZ, length-for-age $Z$-score; WAZ, weight-for-age $Z$-score; WLZ, weight-for-length $Z$-score.

Prevalence was significantly different from that in the other age groups $\left(\chi^{2}\right.$ test): ${ }^{*} P<0.05$. tOnly for children $>6$ months old.

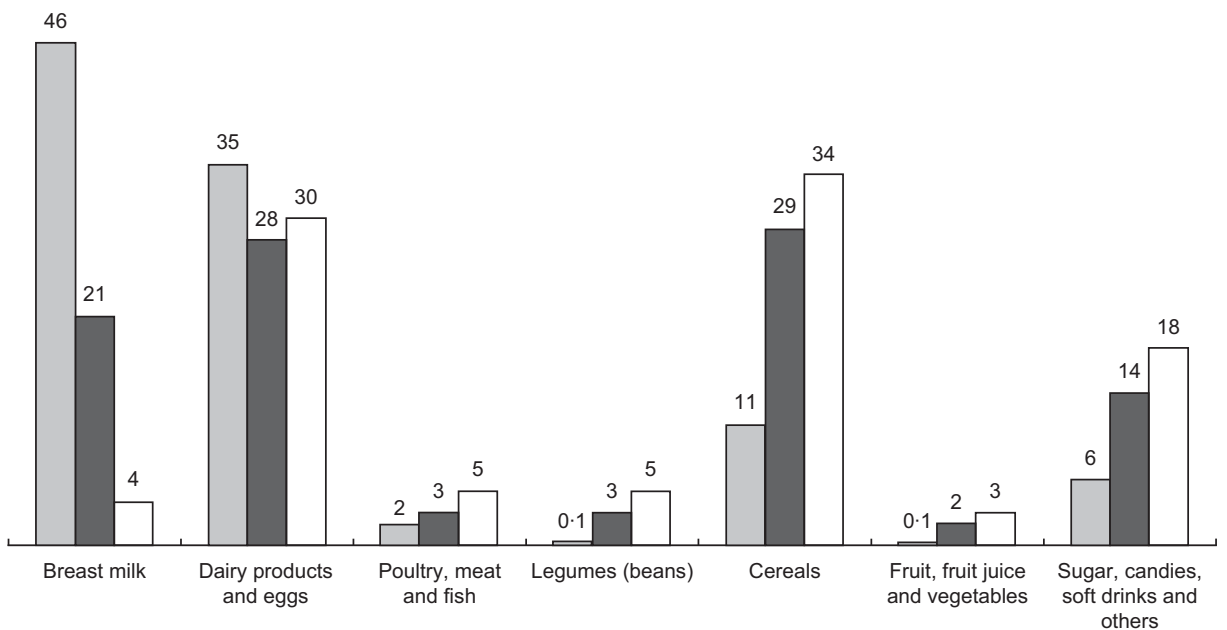

Fig. 1 Contribution (\%) of food groups and breast milk to total energy intake among infants ( $\square, 0-5$ months old; $\square$, 6-11 months old) and toddlers ( $\square, 12-24$ months old), Acre, north-west Brazil (n 69)

stunting and diarrhoea) did not differ across tertiles of the wealth index (data not shown).

Figure 1 illustrates the percentage contribution of complementary foods and breast milk (to total energy intake) according to age group. Among infants aged 0-5 months, the major energy contributors were breast milk followed by non-enriched cow's milk. In the groups of infants (6-11 months) and toddlers, the major food contributors to energy, excluding breast milk among infants, were cereals (especially non-enriched rice and maize flours), non-enriched cow's milk and sugar (from soft drinks, artificial juices and that added to porridges). Low intakes of meat, beans, vegetables and fruits were observed for all groups.

The median daily intakes of energy and nutrients, according to age group, are shown in Table 3. Total energy included energy and nutrients provided by breast milk.
Compared with international recommendations ${ }^{(6,17)}$, the median intakes of protein, riboflavin, vitamin $\mathrm{B}_{12}$ and folate were above the recommendation for all these age groups. Median intakes of ascorbic acid were above the recommendation for infants ( $0-5$ and 6-11 months), while the median intake of thiamin was above the recommended value for children aged $>6$ months. Median intakes of vitamin $\mathrm{A}$, vitamin $\mathrm{B}_{6}$ and $\mathrm{Ca}$ were above the recommended values only for 0-5-month-old infants, 6-11-month-old infants and 12-24-month-old toddlers, respectively. Median intakes of niacin, total $\mathrm{Fe}$, bioavailable $\mathrm{Fe}$ and $\mathrm{Zn}$ were under the recommendations for all age groups. All infants and $92.3 \%$ of toddlers were at risk for inadequate total $\mathrm{Fe}$ intake. Dietary Fe from animal foods contributed on average $0.5 \%$ and $14.3 \%$ to the total Fe intake among infants and toddlers, respectively. 
Table 3 Median daily intakes of energy and selected nutrientst of the children according to age group, Acre, north-west Brazil

\begin{tabular}{|c|c|c|c|c|c|c|}
\hline & \multicolumn{2}{|c|}{$0-5$ months $(n 12)$} & \multicolumn{2}{|c|}{$6-11$ months ( $n 18)$} & \multicolumn{2}{|c|}{ 12-24 months ( $n$ 39) } \\
\hline & Median & IQR & Median & IQR & Median & IQR \\
\hline Energy (kJ) & 2699 & 2113,3421 & 3515 & 2458, 3919 & 4481 & 3477,6586 \\
\hline Energy (kcal) & $645 \cdot 0$ & $505 \cdot 0,817 \cdot 7$ & $840 \cdot 5$ & $587 \cdot 5,936 \cdot 7$ & $1071 \cdot 0$ & $831 \cdot 0,1574 \cdot 0$ \\
\hline Protein $(\mathrm{g})$ & $16 \cdot 0$ & $9 \cdot 5,28 \cdot 6$ & $22 \cdot 8$ & $17 \cdot 0,30 \cdot 9$ & $35 \cdot 1$ & $22 \cdot 7,50 \cdot 0$ \\
\hline Animal protein (q) & $14 \cdot 8$ & $8 \cdot 3,26 \cdot 2$ & $15 \cdot 3$ & $11 \cdot 8,26 \cdot 6$ & $23 \cdot 2$ & $15 \cdot 4,35 \cdot 6$ \\
\hline Protein from meat $(\mathrm{g})$ & 0.0 & $0.0,0.0$ & $0 \cdot 1$ & $0.0,6 \cdot 3$ & $6 \cdot 6$ & $0 \cdot 7,13 \cdot 0$ \\
\hline Vitamin A (RE) & $386 \cdot 0$ & $308 \cdot 7,448 \cdot 7$ & $326 \cdot 0$ & $232 \cdot 7,484 \cdot 5$ & $320 \cdot 0$ & $240 \cdot 0,568 \cdot 0$ \\
\hline Ascorbic acid (mg) & $26 \cdot 0$ & $21 \cdot 2,32 \cdot 7$ & $28 \cdot 5$ & $15 \cdot 7,51 \cdot 5$ & $24 \cdot 0$ & $17 \cdot 0,39 \cdot 0$ \\
\hline Thiamin (mg) & $0 \cdot 16$ & $0 \cdot 1,0 \cdot 2$ & 0.25 & $0.2,0.36$ & 0.4 & $0 \cdot 2,0 \cdot 6$ \\
\hline Riboflavin (mg) & 0.49 & $0 \cdot 3,1 \cdot 1$ & $0 \cdot 7$ & $0.53,0.96$ & 0.95 & $0.6,1.6$ \\
\hline $\operatorname{Niacin}(\mathrm{mg})$ & 0.6 & $0 \cdot 1,1 \cdot 3$ & $1 \cdot 8$ & $1 \cdot 0,2 \cdot 9$ & $3 \cdot 7$ & $2 \cdot 2,6 \cdot 0$ \\
\hline Vitamin $B_{6}(\mathrm{mg})$ & 0.17 & $0.1,0.33$ & 0.4 & $0.3,0.5$ & 0.6 & $0.4,1.0$ \\
\hline Folate (mg) & $35 \cdot 5$ & $34 \cdot 0,49 \cdot 0$ & $60 \cdot 0$ & $47 \cdot 2,79 \cdot 5$ & 83.0 & $62 \cdot 0,131 \cdot 0$ \\
\hline Vitamin $\mathrm{B}_{12}(\mathrm{mg})$ & 0.49 & $0.36,1 \cdot 2$ & $1 \cdot 1$ & $0 \cdot 4,1 \cdot 8$ & $2 \cdot 0$ & $0 \cdot 8,3 \cdot 8$ \\
\hline $\mathrm{Ca}(\mathrm{mg})$ & $425 \cdot 0$ & $240 \cdot 7,872 \cdot 2$ & $492 \cdot 0$ & $367 \cdot 0,638 \cdot 5$ & $559 \cdot 0$ & $453 \cdot 0,895 \cdot 0$ \\
\hline $\mathrm{Fe}(\mathrm{mg})$ & 0.64 & $0 \cdot 4,1 \cdot 0$ & $1 \cdot 6$ & $0 \cdot 9,2 \cdot 3$ & $2 \cdot 8$ & $2 \cdot 0,4 \cdot 8$ \\
\hline Fe from animal foods (mg) & 0.0 & $0.0,0.0$ & 0.01 & $0.0,0.4$ & 0.4 & $0.09,0.9$ \\
\hline Bioavailable Fe $(\mathrm{mg})$ & 0.02 & $0.005,0.07$ & $0 \cdot 1$ & $0.05,0.30$ & $0 \cdot 3$ & $0.2,0.6$ \\
\hline Zn (mg) & $2 \cdot 2$ & $1 \cdot 4,3 \cdot 8$ & $3 \cdot 1$ & $2 \cdot 1,3 \cdot 8$ & $4 \cdot 7$ & $3 \cdot 0,6 \cdot 9$ \\
\hline Bioavailable Zn (mg) & $1 \cdot 4$ & $1 \cdot 2,2 \cdot 2$ & $1 \cdot 5$ & $1 \cdot 1,2 \cdot 1$ & $1 \cdot 7$ & $1 \cdot 1,2 \cdot 8$ \\
\hline
\end{tabular}

$I Q R$, interquartile range; RE, retinol equivalents.

tIncluding energy and nutrients provided from breast milk.

A non-significant trend was found in which median values for $\mathrm{Hb}$ and $\mathrm{SF}$ concentrations increased with increasing tertile of energy-adjusted vitamin $\mathrm{A}(10 \cdot 8,11 \cdot 3$, $11 \cdot 6 \mathrm{~g} / \mathrm{dl}$ for $\mathrm{Hb} ; 7 \cdot 0,8 \cdot 5,13 \cdot 0 \mu \mathrm{g} / \mathrm{l}$ for $\mathrm{SF})$ and total Fe intakes $(11 \cdot 1,11 \cdot 3,11 \cdot 4 \mathrm{~g} / \mathrm{dl}$ for $\mathrm{Hb} ; 13 \cdot 0,7 \cdot 5,9 \cdot 3 \mu \mathrm{g} / 1$ for SF), comparing the lowest to the highest tertiles, respectively ( $P$ for trend $>0 \cdot 05$ ). Frequencies of anaemia, Fe deficiency and Fe-deficiency anaemia were not statistically different across tertiles of energy-adjusted nutrient intakes. However, five of the eight cases of stunted children were in the lowest tertile of energy-adjusted vitamin A intake. The energy-adjusted bioavailable Fe intake was statistically different across tertiles of the wealth index: $0 \cdot 170,0 \cdot 198$ and $0.233 \mathrm{mg} / \mathrm{d}$, comparing the lowest to highest tertiles, respectively ( $P$ for trend $=0 \cdot 043)$.

\section{Discussion}

Our findings should be interpreted cautiously because there are some limitations to the present study. The principal constraint of our study is the cross-sectional design and the small sample size. Thus, we cannot establish a temporal relationship between dietary practices and nutritional status. However, this is the first nutritional survey to assess biochemical Fe status, anthropometric indicators and dietary practices in a randomly selected sample of children under the age of 2 years living in the Brazilian Amazon area. Although Acrelândia and Assis Brasil are examples of Amazonian towns with distinct economic activities, they show very similar childhood health indicators ${ }^{(8)}$. In Brazil, the state of Acre has the second worst childhood development index, with a childhood mortality rate $(34 \cdot 3$ / 1000) higher than that observed for Brazilian children overall $(27 \cdot 7 / 1000)^{(22)}$.

We have not found differences in the frequency of stunting according to tertile of energy and nutrient intakes, except only for energy-adjusted vitamin A intake (with a high proportion of stunting in the lowest tertile of intake). Stunting prevalence in our children (11.6\%) was lower than the values reported in other studies in developing countries, but it should not be neglected ${ }^{(23,24)}$. A previous study carried out in Latin America ${ }^{(25)}$ found the association between feeding practices and stunting to be generally weaker and less consistent among children during the first year of life, increasing gradually with age. The magnitude of this association was greatest among 30-36-month-old children. An additional factor that may explain the greater effect of feeding practices on heightfor-age among older children is the clustering of negative practices and behaviours, with their cumulative effect becoming apparent only after a certain age, possibly starting during the second year of life and likely increasing over time ${ }^{(26)}$.

In the present study, the haematological indicators showed a high prevalence of anaemia, Fe deficiency and Fe-deficiency anaemia among the children. Overall, 30.3\% of the anaemic children did not show evidence of $\mathrm{Fe}$ deficiency. Other nutrient deficiencies could be the cause based on the presence of low dietary intakes of vitamins, especially vitamin A. Unfortunately we did not assess other biochemical indicators that could elucidate the origin of the remaining anaemia. The percentage of anaemia found among these under-twos from Acre was similar to the values reported by $\mathrm{WHO}^{(3)}$ for children from developing 
countries. Higher prevalences of anaemia and Fe deficiency were reported among under-twos in a rural community of South Africa: $65 \cdot 2 \%$ and $43 \cdot 2 \%$, respectively ${ }^{(23)}$. However, in our study the prevalence of anaemia and Fe deficiency was higher than that observed in infants from developed areas. In a longitudinal study of under-twos in Dunedian (New Zealand), Fe deficiency was observed in $7 \%$ of children at 9, 12 and 18 months, and it was absent at 24 months of age ${ }^{(26)}$. Contrary to the results from Heath et $a l^{(26)}$, we found a significant increase in the prevalence of Fe deficiency in toddlers compared with infants.

In our study population, exclusive breast-feeding was interrupted in $83 \cdot 8 \%$ of the infants $<6$ months of age, with early introduction of complementary foods. The frequency of exclusive breast-feeding found in the present study was lower than the prevalence observed in a national sample of $0-5$ month-old Brazilian children ${ }^{(27)}$. The nutritional value and protective immune properties of breast milk as well as the psychosocial benefits of breast-feeding to the infant are widely recognized. Thus the $\mathrm{WHO}^{(3)}$ recommends exclusive breast-feeding during the first 6 months, followed by introduction of additional foods to meet the child's nutrient needs. However, early introduction of complementary food is still a common practice in many developing countries, and the inclusion of non-breast-milk foods and beverages in the child's diet before the age of 6 months increases the risk for nutrient imbalances/deficiencies and infectious diseases ${ }^{(28,29)}$. A longitudinal study realized with Vietnamese children concluded that over the age range from 1 month to 4 years, $Z$-scores for all anthropometric indices (weight-forage, height-for-age and weight-for-height) of the children who received complementary food were significantly lower than those of the children who were exclusively breast-fed for at least 3 months. In the same study, morbidity from diarrhoea and acute respiratory infections was significantly lower for the $>3$ months exclusively breastfed group, compared with the group that was exclusively breast-fed for $<3$ months ${ }^{(30)}$. Similar results were found by Victora et $a l^{(28)}$ in a population-based case-control study carried out in two urban areas in Brazil, reporting that the type of milk in an infant's diet was an important risk factor for death from diarrhoeal and respiratory infections. We found a high prevalence of recent diarrhoea $(39 \cdot 1 \%)$ among our children that may be due to the combined effects of reduced time of exclusive breastfeeding, early introduction of complementary foods, and crowded and unsanitary living conditions ${ }^{(8)}$ (subjects' domiciles often had high a number of people per bedroom and lacked a sanitation system).

Analysis of food group intakes showed a high content of carbohydrates and porridges made from cow's milk and non-enriched flours and of low quantities of meat, vegetables and fruits. Faber and Benadé(23) and Hotz and Gibson $^{(1)}$ found similar food intake patterns among infants and toddlers from rural areas in South Africa and Malawi, respectively. In these studies, mostly carbohydrates and less frequently fruits, vegetables, meat, Fe, vitamin A and vitamin C contributed to the energy content of complementary diets. In our study, cow's milk intake represented $35 \cdot 2 \%$, $28 \cdot 1 \%$ and $30.0 \%$ of the total energy consumed by infants (0-5 months), infants (6-11 months) and toddlers (12-24 months), respectively. A Brazilian national survey ${ }^{(27)}$ showed among 0-5-month-old and 6-12-month-old children that the presence of other milks in the complementary feeding (excluding breast milk) was $51 \cdot 1 \%$ and $73 \cdot 1 \%$, respectively. Several studies have already shown the deleterious effect on Fe nutritional status of the introduction of cow's milk in the diet of the under-twos ${ }^{(5,29,31)}$. Soh et al. ${ }^{(5)}$ found among 6-24-month-old New Zealanders receiving $>500 \mathrm{ml}$ cow's milk/d that there was a decrease of $25 \%$ in $\mathrm{SF}$ values. Another Brazilian study showed a significant positive association between cow's milk intake and anaemia risk among children $<5$ years old and reported a possible inhibitory effect of cow's milk on the absorption of Fe from other foods ${ }^{(31)}$.

Low contents of Fe, bioavailable Fe and vitamins $\mathrm{C}$ and $\mathrm{A}$ observed in the complementary feeding adopted by our children were also observed in other studies from developing countries, where feeding practices based on cereals and legumes negatively influence Fe bioavailability from plant-based complementary foods, with relatively high amounts of phytic acid and negligible amounts of ascorbic $\operatorname{acid}^{(32)}$. The intake levels of bioavailable Fe were positively associated with the wealth index in our study population, suggesting that socio-economic improvements can have some impact on the quality of children's diet in this setting. Low intakes of total Fe and bioavailable Fe can be the cause of the high rates of Fe deficiency observed in our study population. Another cross-sectional study ${ }^{(5)}$ investigated food sources and dietary factors associated with SF levels in 6-24-month-old children and found that intakes of total $\mathrm{Fe}$ (from diet and supplemented) and vitamin $\mathrm{C}$ were positively associated with SF levels, after controlling for possible confounders.

Similar to previous studies carried out in other developing countries ${ }^{(1,4,23)}$, we found low intakes of $\mathrm{Ca}$ and $\mathrm{Zn}$, where the median intake of $\mathrm{Ca}$ was above the recommendation only for toddlers. There is no conclusive evidence showing that suboptimal $\mathrm{Ca}$ intake leads to a clinical or subclinical deficiency state or contributes to linear growth faltering ${ }^{(1)}$. The most convincing evidence for the role of a specific nutrient deficiency in causing linear growth faltering among young children has been reported for $\mathrm{Zn}$ deficiency ${ }^{(33)}$.

Given the detrimental consequences of early childhood malnutrition for health and development, there is an urgent need to promote exclusive breast-feeding in the first 6 months of life and to improve complementary feeding. From our results we highlight that it is necessary to conduct nutritional education and intervention programmes addressing dietary micronutrient deficiencies, 
especially focusing on complementary diets with high bioavailable Fe content. Additionally, the recommendation for exclusive breast-feeding in the first 6 months of life should be reinforced and action to improve the dietary bioavailability of $\mathrm{Zn}, \mathrm{Fe}$ and other nutrients should be taken.

\section{Acknowledgements}

Sources of funding: The study was funded by the Conselho Nacional de Desenvolvimento Científico e Tecnológico - CNPq (grant no. 50.2937/2003-3 and 551359/2001-3) and the Fundação de Amparo à Pesquisa do Estado de São Paulo - FAPESP (grant no. 03/12491-7). Conflict of interest declaration: There is no interest conflict. Authorship responsibilities: T.G.C. and M.A.C. were responsible for the study design, project management, data analysis, interpretation of the results and manuscript writing. L.G.B. was responsible for data analysis and the interpretation of results. P.T.M. was responsible for the study design, project management and manuscript writing. Acknowledgements: Our sincere appreciation to $\mathrm{CNPq}$ and FAPESP for funding. We thank Francisca Souza Santiago for her technical support and the mothers and guardians who participated in the study.

\section{References}

1. Hotz C \& Gibson RS (2001) Complementary feeding practices and dietary intakes from complementary foods among weanlings in rural Malawi. Eur J Clin Nutr 55, 841-849.

2. Victora CG, Kirwood BR, Ashworth A, Black RG, Rogers S, Sazawal S, Campbell H \& Gove S (1999) Potential interventions for the prevention of childhood pneumonia in developing countries: improving nutrition. Am J Clin Nutr 70, 309-320.

3. World Health Organization (2001) Iron Deficiency Anaemia. Assessment, Prevention and Control. A Guide for Programme Managers. WHO/NHD/O.13. Geneva: WHO.

4. Gibson RS, Ferguson EL \& Lehrfeld J (1998) Complementary foods for infant feeding in developing countries: their nutrient adequacy and improvement. Eur J Clin Nutr 52, 764-770.

5. Soh P, Ferguson EL, McKenzie JE, Skeaff S, Parnell W \& Gibson RS (2002) Dietary intakes of 6-24-month-old urban South Island New Zealand children in relation to biochemical iron status. Public Health Nutr 5, 339-356.

6. Dewey KG \& Brown KH (2003) Update on technical issues concerning complementary feeding of young children in developing countries and implications for intervention programs. Food Nutr Bull 24, 5-28.

7. Cardoso MA, Ferreira MU, Camargo LMA \& Szarfarc SC (1994) Anaemia, iron deficiency and malaria in a rural community in Brazilian Amazon. Eur J Clin Nutr 48, 326-332.

8. Muniz PT, Castro TG, Araujo T, Nunes NB, Silva-Nunes M, Hoffmann EH, Ferreira MU \& Cardoso MA (2007) Child health and nutrition in the Western Brazilian Amazon: population-based surveys in two counties in Acre State. Cad Saude Publica 23, 1283-1293.
9. Lohman TG, Roche AF \& Martorell R (editors) (1988) Anthropometric Standardization Reference Manual. Champaign, IL: Human Kinetics Books.

10. Dean AG, Dean AJ, Coulombier D, Burton AH, Brendel KA, Smith DC, Dicker RC, Sullivan KM \& Fagan RF (1994) Epi Info, Version 6: A Word Processing Database, and Statistics Program for Epidemiology on Microcomputers. Atlanta, GA: Centers for Disease Control and Prevention.

11. World Health Organization (2006) WHO Child Growth Standards: Length/Height-for-age, Weight-for-age, Weightfor-length, Weight-for-height and Body Mass Index-for-age: Methods and Development. Geneva: WHO.

12. DeMayer EM, Dallman P, Gurney JM, Hallberg L, Sood SK \& Srikantia SG (1989) Preventing and Controlling Iron Deficiency Anaemia through Primary Health Care. Geneva: WHO.

13. Wharf SG, Fox TE, Fairweather-Tait SJ \& Cook JD (1997) Factors affecting iron stores in infants $4-18$ months of age. Eur J Clin Nutr 51, 504-509.

14. Drewett RF, Woolridge MW, Jackson DA et al. (1989) Relationships between nursing patterns, supplementary food intake and breast-milk intake in a rural Thai population. Early Hum Dev 20, 13-23.

15. Nejar FF, Segall-Corrêa AM, Rea MF, Vianna RP \& Panigassi G (2004) Breastfeeding patterns and energy adequacy. Cad Saude Publica 20, 64-71.

16. Food and Agriculture Organization of the United Nations/ World Health Organization/International Atomic Energy Agency (1996) Trace Elements in Human Nutrition and Health. Geneva: WHO.

17. World Health Organization (1998) Complementary Feeding of Young Children in Developing Countries: A Review of Current Scientific Knowledge. Geneva: WHO.

18. US Department of Agriculture (2008) Food and Nutrient Database for Dietary Studies, 3.O. Beltsville, MD: Agricultural Research Service, Food Surveys Research Group.

19. World Health Organization (1991) Indicators for Assessing Breast Feeding Practices. WHO/CDD/SER/91.14. Geneva: WHO.

20. Filmer D \& Pritchett LH (2001) Estimating wealth effects without expenditure data - or tear: an application to educational enrolments in states of India. Demography 38, $115-132$.

21. Willett WC, Howe GR \& Kushi LH (1997) Adjustment for total energy intake in epidemiologic studies. Am J Clin Nutr 65, Suppl. 4, S1220-S1228.

22. UNICEF (2001) The State of the World's Children 2001. http://www.unicef.org/sowc01 (accessed January 2009).

23. Faber M \& Benadé AJS (1999) Nutritional status and dietary practices of 4-24-month-old children from a rural South African community. Public Health Nutr 2, 179-185.

24. Siegel EH, Stoltzfus RJ, Khatry SK, LeClerq SC, Katz J \& Tielsch JM (2006) Epidemiology of anaemia among 4- to 17 -month-old children living in south central Nepal. Eur J Clin Nutr 60, 228-235.

25. International Food Policy Research Institute, Food Consumption and Nutrition Division (2002) Creating a Child Feeding Index using the Demographic and Health Surveys: An Example from Latin America. Washington, DC: IFPRI.

26. Heath ALM, Tuttle CR, Simons MSL, Cleghorn CL \& Parnell WR (2002) Longitudinal study of diet and iron deficiency anaemia in infants during the first two years of life. Asia Pac J Clin Nutr 11, 251-257.

27. Ministério da Saúde (2008) Pesquisa Nacional Sobre Demografia e Saúde da Criança e da Mulher-Relatório. Brasília, DF: Ministério da Saúde.

28. Victora CG, Vaughan JP, Lombardi C, Fuchs SMC, Gigante DP, Smith PG, Nobre LC, Teixeira AMB, Moreira LB \& Barros FC (1987) Evidence for protection by breast-feeding 
against infant deaths from infectious diseases in Brazil. Lancet 2, 319-321.

29. Monterrosa EC, Frongillo EA, Vásquez-Garibay EM, Romero-Velarde E, Casey LM \& Willows ND (2008) Predominant breast-feeding from birth to six months is associated with fewer gastrointestinal infections and increased risk for iron deficiency among infants. $J$ Nutr 138, 1499-1504.

30. Hop LT, Gross R, Giay T, Sastroamidjojo S, Schultnik W \& Lang NT (2000) Premature complementary feeding is associated with poorer growth of Vietnamese children. J Nutr 130, 2683-2690.

31. Levy-Costa RB \& Monteiro CA (2004) Consumo de leite de vaca e anaemia na infância no Município de São Paulo. Rev Saude Publica 38, 797-803.

32. Davidsson L (2003) Approaches to improve iron bioavailability from complementary foods. J Nutr 133, 1560-1562.

33. Brown KH, Peerson JM \& Allen LH (1998) Effect of zinc supplementation on children's growth: a meta-analysis of intervention trials. Bibl Nutr Dieta 54, 76-83. 